\title{
AKULTURASI BUDAYA SOSIAL DAN MAKNA SIMBOLIK TARI DERO
}

\author{
Andi Imrah Dewi ${ }^{*}$, Andi Febri Herawati \\ ${ }^{1}$ Program Studi PGSD, Fakultas Keguruan dan Ilmu Pendidikan, Universitas Tadulako \\ ${ }^{2}$ Program Studi Ilmu Komunikasi, Fakultas Ilmu Sosial dan Ilmu Politik, Universitas \\ Tadulako \\ *Email: andiimrahdewiandi@yahoo.co.id
}

\begin{abstract}
The process of acculturation runs very quickly or slowly depending on the perception of the local community towards the incoming foreign culture. The purpose of the study is to find out the cultural acculturation and symbolic meaning of dero dance. Research methods use a qualitative approach, with a single case study design. Data collection techniques through observation, interviews, and documentation studies. The results of the study that dero dance has a common meaning as a form of gratitude and a sense of community unity regardless of social strata but the meaning and value shifted due to the acculturation of foreign cultures using modern music collaborated with other cultures. The special meaning of the dero dance movement is a simple and simultaneous presentation of motion in doing and has its attraction that can give suggestions and feel the desire of everyone to participate in doing dero dance moves. This type of dance is a popular traditional dance that can be followed and pulled with the whole community in the event of a traditional party and dero dance is a social dance from various circles considering that this dero dance aims to unite the movement. Dero dance is performed at the traditional ceremony of the wedding and thanksgiving party. The meaning of the floor pattern of the circle shape that is not broken and well maintained as a form of mutual help.
\end{abstract}

Keywords: Cultural Acculturation; Art; Symbolic Meaning; Dero Dance

\begin{abstract}
ABSTRAK
Proses akulturasi berjalan sangat cepat atau lambat sangat tergantung dari persepsi masyarakat setempat terhadap budaya asing yang masuk. Tujuan penelitian yaitu untuk mengetahui akulturasi budaya dan makna simbolik tarian dero. Metode penelitian menggunakan pendekatan kualitatif, dengan desain kajian kasus tunggal. Teknik pengumpulan data melalui observasi, interview (wawancara mendalam), dan studi dokumentasi. Hasil penelitian bahwa tarian dero memiliki makna umum sebagai bentuk rasa syukur dan rasa persatuan masyarakat tanpa memandang strata sosial namun makna dan nilai tersebut bergeser disebabkan adanya akulturasi budaya asing dengan menggunakan musik moderen yang dikolaborasi dengan budaya lain. Pada keistimewaan makna gerak tari dero merupakan sebuah sajian gerak yang sederhana dan serempak di lakukan serta memiliki daya tarik tersendiri yang mampu untuk memberikan sugesti dan merasang keinginan semua orang untuk ikut terlibat dalam melakukan gerak tari dero. Jenis tarian ini adalah tarian tradisi kerakyatan yang mampu di ikuti dan di tarikan dengan seluruh masyarakat dalam ajang pesta adat dan tarian dero merupakan tarian pergaulan dari berbagai kalangan mengingat bahwa tari dero ini tujuanya adalah mempersatukan gerak. Tari dero di tampilkan pada upacara adat pesta perkawinan dan syukuran. Makna pola lantai bentuk lingkaran yang tidak putus dan terjaga dengan baik sebagai bentuk gotong royong.
\end{abstract}

Kata Kunci: Akulturasi Budaya; Seni; Makna Simbolik; Tari Dero

Submisi: 13 Desember 2021 


\section{Pendahuluan}

Kebudayan dalam persepsi kajian budaya merupakan medan nyata tempat berpijaknya berbagai praktik, representasi, bahasa, dan kebiasaan suatu masyarakat tertentu. Kebudayaan juga merupakan bentuk-bentuk kontradiktif akal sehat yang sudah mengakar dan ikut membentuk kehidupan sehari-hari (lihat Sulasman dan Setia Gumilar, 2013:76). Jauh sebelumnya. Imrah, (2020) dalam Koentjaraningrat telah mengemukakan bahwa kebudayaan adalah keseluruhan sistem gagasan, tindakan, dan hasil karya manusia dalam kehidupan masyarakat, yang dijadikan milik dari yang diperoleh dengan cara belajar. Dalam konteks ini, kesenian menjadi bagian yang tidak terpisahkan dari kehadiran kebudayaan secara menyeluruh.

Kebudayaan asing itu lambat laun diterima dan diolah ke dalam kebudayaannya sendiri tanpa menyebabkan hilangnya unsur kebudayaan kelompok itu sendiri. Akulturasi adalah suatu proses sosial yang timbul manakala suatu kelompok manusia dengan kebudayaan tertentu dihadapkan dengan unsur dari suatu kebudayaan asing. Kuntowijoyo (2006:31) menyebutkan bahwa ada dua hal pada masyarakat tradisional yang memberi sumbangan pada kehadiran seni. Pertama, faktor pengalaman yang memberikan rangsangan yang kuat buat generasi untuk berekspresi budaya. Kedua, faktor lingkungan sosial yang memberikan sumbangan dalam aktivitas budaya, adat istiadat, maupun etnisitas yang memiliki kekhasan atau keunikan dalam setiap bentuk ekspresi budaya. Kebudayaan menjadi pedoman dasar berupa pengetahuan, kepercayaan, dan nilai-nilai bagi masyarakat dalam menjalankan kehidupan sehari-hari, dalam berbagai tindakan yang dialihkan kepada generasi selanjutnya melalui proses pendidikan.

Sosial yang merupakan hal yang penting dalam melakukan komunikasi dan intraksi yang dapat menumbuhkan semangat untuk saling mengenal satu dan yang lainya dalam bergaul atau bersilaturahmi.
Akulturasi kebudayaan terjadi karena unsur budaya yang baru dinilai memberikan manfaat bagi kehidupansuatumasyarakat. Dilansir dari e-Modul Sosiologi, akulturasi dapat diartikan sebagai proses sosial yang timbul apabila suatu kelompok manusia dengan suatu kebudayaan tertentu dihadapkan dengan unsur-unsur kebudayaan asing yang sedemikian rupa. Maka dari itu, unsur-unsur kebudayaan asing yang ada lambat laun diterima dan diolah ke dalam kebudayaan sendiri tanpa menghilangkan sifat khas kepribadian kebudayaan. Proses akulturasi berjalan sangat cepat atau lambat sangat tergantung dari persepsi masyarakat setempat terhadap budaya asing yang masuk. Apabila masuknya melalui proses pemaksaan, maka akulturasi memakan waktu yang relatif lama. Sebaliknya, apabila masuknya melalui Proses damai, maka akulturasi tersebut akan berlangsung relatif lebih cepat. Syarat terjadinya proses akulturasi, yaitu: Persenyawaan (affinity) atau penerimaan kebudayaan tanpa rasa terkejut; Keseragaman (homogenity), seperti bahasa, teknologi, kemasyarakatan, agama, kesenian, maupun ilmu pengetahuan yang merupakan kontak budaya.

Proses akulturasi budaya dapat terjadi pada masyarakat mana pun, misalnya yang terjadi dalam tarian dero pada masyarakat suku Pamona, Kabupaten Poso. Budaya dero adalah tarian sebagai bentuk rasa syukur dan rasa persatuan masyarakat tanpa memandan strata sosial yang awalnya dilakukan masyarakat Poso, Sulawesi Tengah, namun kemudian tarian ini memiliki pergeseran nilai disebabkan adanya akulturasi budaya. Hal ini juga bisa diakibatkan kemajuan teknologi sehingga tarian dero kemudian kehilangan maknanya baik itu makna simbolik maupun normanorma sosial yang positif. Hal ini dikarenakan masyarakat yang melakukan tradisi ucapan syukur ini telah terkontaminasi dengan pemaknaan kota yang lebih individual dan cenderung bersifat pasif. Hal ini diperburuk dengan masuknya nilai-nilai budaya barat yang disalah tafsirkan oleh masyarakat setempat sebagai 
sebuah budaya baru yang dapat dikolaborasikan dengan tarian asli. Misalnya masuknya alat-alat musik modern yang menggantikan musik tradisional didukung sound system (Pengeras Suara) yang memadai. Dampak budayanya dapat dilihat dengan fenomena beberapa orang saja yang memahami syair lagu, dan peserta lain hanya diam membisu. Selain itu jenis lagu yang dinyayikan terkesan monoton, (Kamarul, 2020).

Terjadinya proses akulturasi budaya sosial dalam hal ini tarian dero diharapkan tidak mengubah makna yang sesungguhnya, karena tarian dero memiliki makna yang lebih dalam khususnya bagi masyarakat Suku Pamona, Kabupaten Poso. Makna yang dibuat merupakan hasil cipta karya manusia terdahulu yang disepakati secara bersama-sama sehingga terbentuklah budaya yang harus dilestarikan secara turuntemurun.

\section{Akulturasi Budaya}

Kebudayaan menjadi hal yang sangat penting bagi masyarakat sebagai bentuk perkembangan dan terintegrasi sebagai ciri hidup masyarakat berupa tradisi ataupun kebiasaan yang mengakar dalam masyarakat. Suatu tradisi masyarakat yang pada hakekatnya merupakan warisan dari para leluhurnya yang merupakan bagian dari budaya bangsa. Hal ini berguna sebagai strategi untuk menjamin eksistensi bangsa, membentuk dan mengembangkan kepribadian serta menata kehidupan bangsa (Mame, 1998)

Kebudayaan merupakan persoalan yang sangat kompleks dan luas, misalnya kebudayaan yang berkaitan dengan kehidupan manusia, adat istiadat dan tata karma. Kebudayaan sebagai bagian dari kehidupan, cenderung berbeda antara satu suku dengan suku lainnya, khususnya di Indonesia. Masyarakat Indonesia masih mempertahankan adat istiadat dan kebiasaannya yang berbeda hingga sampai saat ini, termasuk adat kesenian (Casalba, 1967). Kebudayaan adalah keseluruhan gagasan dan karya manusia yang harus dibiasakandengan belajar, beserta keseluruhan dari hasil budi dan karyanya (Koentjaraningrat, 2016).

Menurut C. Kluckhom dalam (Soerjono Soekanto, 2012) bahwa, Tujuh unsur kebudayaan yang dianggap sebagai cultural universal, yaitu: (1) Pakaian, perumahan, alat-alat rumah tangga, senjata, alat-alat produk, transpor, dan sebagainya. (2) Mata pencaharian hidup dan sistemsistem ekonomi (pertanian, peternakan, sistem produksi, sistem distribusi, sistem distribusi dan sebagainya). (3) Organisasi sosial (sistem kekerabatan, organisasi politik, sistem hukum, sistem perkawinan). (4) Bahasa (lisan maupun tertulis). (5) Kesenian (Seni rupa, seni suara, seni gerak, dan sebagainya). (6) Sistem pengetahuan. (7) Religi (sistem kepercayaan).

Koentjaraningrat (2000), ia berpendapat bahwa Akulturasi dalam kamus ilmiah populer diartikan sebagai proses pencampuran dua kebudayaan atau lebih. Dalam akulturasi atau acculturation atau culture contact diartikan oleh para sarjana antropologi mengenai proses sosial yang timbul bila suatu kelompok manusia dengan suatu kebudayaan tertentu dihadapkan dengan unsurunsur dari suatu kebudayaan asing dengan sedemikian rupa sehingga unsur-unsur kebudayaan asing itu lambat laun diterima dan diolah dalam kebudayaan sendiri tanpa menyebabkan hilangnya kepribadian kebudayaan itu sendiri.

Nardy (2012: 142) menjelaskan Akulturasi (acculturation atau culturecontact) adalah proses sosial yang timbul bila suatu kelompok manusia dengan kebudayaan tertentu dihadapkan dengan unsur-unsur dari suatu kebudayaan asing dengan sedemikian rupa, sehingga unsurunsur kebudayaan asing itu lambat laun diterima dan diolah ke dalam kebudayaan sendiri tanpa menyebabkan hilangnya kepribadian kebudayaan itu sendiri. 


\section{Komunikasi dan Makna Pesan}

Mulyana (2004) Komunikasi adalah suatu kebutuhan pokok bagi manusia. Fungsi komunikasi sebagai komunikasi sosial dapat mengisyaratkan bahwa komunikasi itu sangat penting untuk membangun konsep dalam diri, untuk kelangsungan hidup, untuk memperoleh kebahagiaan, dan terhindar dari ketegangan dan tekanan antara lain dengan melalui komunikasi yang menghibur, dan juga untuk memupuk hubungan luas dengan orang lain. Mulyana menambahkan lagi bahwa bahwa setiap praktik komunikasi pada dasarnya adalah representasi budaya, atau tepatnya suatu peta atas suatu realitas budaya yang sangat rumit. Lebih lanjut Mulyana mengatakan bahwa begitu kita mulai berbicara tentang komunikasi, tak terhindarkan, kita pun berbicara tentang budaya.

Makna adalah hubungan antara suatu objek dengan lambangnya. Makna pada dasarnya terbentuk berdasarkan hubungan antara lambang komunikasi (simbol), akal budi manusia penggunanya (objek) (Verdiansyah:2004)

Menurut Cangara (2006) pesan yang dimaksud dalam proses komunikasi adalah sesuatu yang disampaikan pengirim kepada penerima. Pesan dapat disampaikan dengan cara tatap muka atau media komunikasi. Isinya bisa berupa ilmu pengetahuan, hiburan, informasi, nasihat atau propaganda. Pesan pada dasarnya bersifat abstrak. Untuk membuatnya konkret agar dapat dikirim dan diterima oleh komunikan, manusia dengan akal budinya menciptakan sejumlah lambang komunikasi berupa suara, mimik, gerak-gerik, bahasa lisan, dan bahasa tulisan.

\section{Konseptualisasi Penelitian}

Penelitian yang dilaksanakan ini merupakan penelitian dengan menggunakan pendekatan kualitatif, dengan menggunakan desain kajian kasus tunggal. Penelitian dilaksanakan untuk mengkaji Pendekatan teoretik Interdisiplin dipilih untuk memahami dan menjelaskan foenomena yang diteliti. Menurut Rohidi (2011) pendekatan interdisplin merupakan pengambilan konsep dan teori disiplin yang disusun dalam bentuk satuan teori yang menjadi landasan metodologis untuk memetakan, menganalisis, dan menginterpretasi pelaksanaan dan hasil penelitian. Sumber data dalam penelitian ini terdiri atas data primer serta data sekunder (Rohidi, 2011). Pertama, data primer adalah yang diperoleh melalui pengamatan langsung oleh peneliti terhadap realita yang ada di lapangan, Data pada penelitian ini dikumpulkan melalui teknik Observasi (pengamatan), interview (wawancara mendalam), dan studi dokumentasi. Berikut dirinci pengumpulan data pada tiap teknik pengumpulan data. Matris Pengumpulan Data memudahkan pelaksanaan pengumpulan data, Rohidi (2011) menyarankan agar peneliti sebelum masuk kelapangan, harus mempersiapkan rancangan atau garis besar kegiatan pengumpulan data di lapangan. Garis besar kegiatan tersebut berupa matriks pengumpulan data yang berisikan masalah penelitian, konsep-konsep yang digunakan. dan beberapa garis-garis besar kegiatan yang akan dilaksanakan pada saat penelitian berlangsung. Berikut disajikan matriks pengumpulan data penelitian ini.

\section{Hasil Dan Pembahasan \\ Nilai Pendidikan dalam Tari Dero}

Kontak budaya dalam situasi bersahabat atau situasi bermusuhan. Kontak budaya antara kelompok yang menguasai dan dikuasai dalam seluruh unsur budaya, baik dalam ekonomi, Akulturasi sendiri bisa terjadi melalui kontak budaya yang bentuknya bermacam-macam, antara lain sebagai berikut. Kontak sosial pada seluruh lapisan masyarakat, sebagian masyarakat, atau bahkan antarindividu dalam dua masyarakat. Tari dero merupakan paketan gerak yang saling memadu menjadi satu dan tak dapat terpisahkan walau dengan gerak sederhana namun memberikan daya tarik tersendiri kepada penari maupun penikmat yang melihat pertunjukan tari dero unsur gerak yang memberikan konsep 
kesederhanaan dari aktivitas yang terjadi di masyarakat suku Pamona tentunya memiliki keistimewaan yang membuat tari dero merupakan tariaan yang sangat enerji dan memiliki karakter pawor yang kuat dalam merespon masyarakat untuk bergabung berdendang Bersama dalam suka cita menikmati pesta adat dan upacara adat lainya

$\begin{array}{rr}\text { Tarian } & \text { dero memiliki nilai } \\ \text { pendidikan } & \text { untuk mempersatukan }\end{array}$
masyarakat yang tidak memandang strata sosial mereka intinya bersatu dan bersama semua harus berpengang tanggan dan ikut bergembira ini menandakan bahwa mereka sangat menjunjung sportifitas rasa kepedulian yang tinggi memberikan cerminan karakter budaya memberikan nilai-nilai Pendidikan yang berangkat dari strukutur gerak dero yang mengajarkan banyak hal tentang bagaimana budaya memberikan cerminat untuk membangun karakter peserta didik dalam bergotong royong ,bahu membahu, sprortif sebagai bagian dari nilai Pendidikan yang di tanamkan oleh budaya suku pamona yang hadir di masyarakatnya yang mengadung unsur kedamaian dan keindahan dari pesona yang di tampilkan.

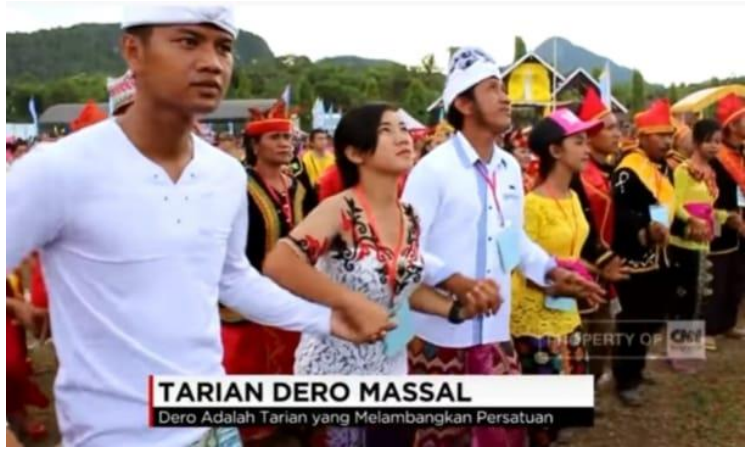

Gambar 1 Dokumentasi CNN Indonesia gerak dero yang saling bergandengan tangan satu dengan yang lain melambangkan persatuan (2016)

Syamsidi SYAMSIDI. M, Lono L Siamtupang (2010). Fungsi simbol adalah sebagai berikut (1) sebagai pengetahuan ditemukan fungsi dero pada kategori gagasan kolektif, tatanan masyarakat, pandangan hidup, solidaritas kelompok dan pranata estetika; (2) sebagai komunikasi hanya ditemukan fungsi dero pada kategori komunikasi; (3) sebagai partisipasi ditemukan fungsi dero pada kategori penciptaan peranan masyarakat dan penciptaan pranata status sosial; (4) sebagai mediasi ditemukan fungsi dero pada kategori mediasi pendidikan masyarakat, mediasi kasih sayang, mediasi kebersamaan, dan mediasi ekspresi keindahan. Mediasi perdamaian jika dilihat dari makna simbol dero, mengarah pada kesatupaduan masyarakat untuk membangun Kabupaten Poso dengan tidak terjebak pada masyarakat

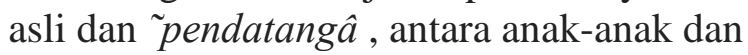
orang tua, laki-laki dan perempuan, serta pemerintah dan masyarakat sipil. Sementara dari fungsi dero, mediasi perdamaian tercermin dalam sikap kebersamaan yang dilandasi oleh keterbukaan, keinginan untuk maju dan motivasi membangun daerah. Ketiadaan struktur tersebut sebagai wujud struktur baru dengan tidak melihat status, jabatan, usia, golongan dan agama.

Tarian dero dilakukan secara masal atau berkelompok tari dero ini berasal dari disuku pamona dimana tarian ini sangatlah berarti yang merupakan ungkapan rasa syukur yang begitu dalam kepada Tuhan yang melambangkan suka cita dan kebahagian dan tarian ini masih terus di pertahankan sampai sekarang selain itu tari dero sudah mendapatkan penghargaan dari rekor Muri dengan jumlah penari kurang lebih lima ribu orang yang bergabung bersama untuk mempererat silaturahmi dan kebersamaan dalam persatuan

Keistimewaan tarian dero dalam novelty atau temuan dalam penelitian ini ada pada nilai-nilai yang terkandung dalam gerak ini melalui pengamatan dan analisis mendalam melalui studi kasus bahwa tarian dero mengandung nilai kebangsaaan yang mempersatukan berbagai budaya suku adat tanpa terkecuali seperti pada konsep profil pelajar Pancasila pada program sekolah Pengerak yang masuk pada ciri profil pelajar pancasila yang tersampaikan adalah konsep KetuhaanYME,kebinekaan global,gotong royong,kreatif,bernalar kritis,kemandirian untuk belajar dan mengembangkan potensi 
yang di miliki,belajar dari diri dan belajar dari pengalaman tentunya akan memberikan warna yang sangat berarti untuk sebuah ilmu dan pengetahuan .

\section{Makna Simbol Tari Dero Dalam Struktur Geraknya}

Makna gerak tari dero merupakan sebuah sajian gerak yang sederhana dan serempak di lakukan serta memiliki daya tarik tersendiri yang mampu untuk memberikan sugesti dan merasang keinginan semua orang untuk ikut terlibat dalam melakukan gerak tari dero . jenis tarian ini adalah tarian tradisi kerakyatan yang mampu di ikuti dan di tarikan dengan seluruh masyarakat dalam ajang pesta adat dan tarian dero merupakan tarian pergaulan dari berbagai kalangan mengingat bahwa tari dero ini tujuanya adalah mempersatukan gerak di mulai dari Gerakan kaki dengan melakukan langka kaki kanan dua kali dan kiri satu kali sambal terus berputar membuat lingkaran dan berpengang tanggan menari bersama dan tidak boleh putus dari lingkaran harus tetap Bersatu dan bersama sama .Hal ini tentunya unik karena di balik dari simbol komposisi tari dero dan pola lantai yang di mainkan memberikan ruang yang luas untuk dapat berinteraksi dan berkomunikasi saling mengenal satu dan lainya dengan suasana yang penuh dengan kegembiraan. Selain itu tari dero ini untuk garis lingkaran yang di lakukan dari lingkaran kecil kebesar dalam maknanya merupakan wujud pradaban kehidupan yang bersiklus dan terus berputar bagi roda kehidupan dan komposisi ini di lakukan secara kontiyu dari awal sampai akhir pertunjukan begitu besar kekuatan makna simbolik yang di sampaikan dalam tari dero ini bagaimana menghayati proses kehidupan yang lebih Jeneral dan Fleksibel dalam konsep kesederhanaan.

\section{Makna Musik Pengiring Tari Dero}

Makna dari musik pengiring Tari dero adalah sebuah pertunjukan yang diiringi oleh musik tradisional Nggongi dan Ganda. Selain musik yang mengiringi juga berpadu dengan pengiring vocal. Tari Dero yang bertugas untuk menyanyikan syair atau sebuah pantun. Namun, seiring dengan perkembangan zaman alat musik yang digunakan pun tidak harus Nggongi atau Ganda.Musik iringan tari dero sudah berpadu dengan musik tradisi dan modern yang lebih semarak dan lebih menarik dalam sajian iringan yang memacu untuk semangat dan tetap semar dalam nuasa musik etnik yang di mainkan oleh para pemain musik.

\section{Makna Pola Lantai Tari Dero}

Makna pola tari dero sempel dan sederhana cukup dengan lingkaran sudah mewakilkan dari berbagia unsur yang ada seperti pada garis lingkaran:

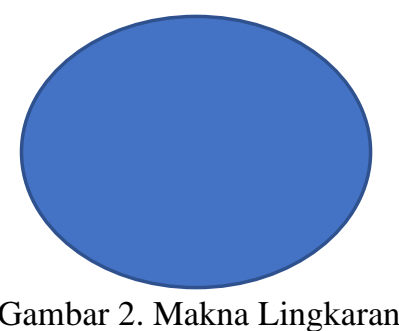

Garis lingkaran memiliki sentuhan yang dalam komunikasi bahasa seni dalam pola lantai yang memberikan arahan bagi para penari untuk taat dalam melakukan Gerakan sesuai dengan arahan dan pola lantai yang sudah di sepakati Bersama dan terus menjaga konsistensi Gerakan untuk terus berkonsentarsi agar mempertahankan bentuk lingkaran yang tidak putus dan terjaga dengan baik dengan cara saling bergotong royong dan melengkapi kelebihan dan kekurangan mengingat tari dero ini bisa dengan waktu durasi yang pendek 5 menit maupun dalam waktu berjam tergantung kesepakatan para penarinya sehingga tari dero jika di lakukan dalam konten pesta upacara syukuran dan penikahan atau yang lainya tentunya bisa lama dan saling bergantian juga bisa semua di lihat dari kondisi yang ada 


\section{Makna Kostum Tari Dero}

Kostum Tari dero lebih menyesuikan pada konten Ketika tari dero di tampilkan pada upacara adat pesta perkawinan dan syukuran lebih kepada kostum adat suku pamona dan bisa dengan kostum bebas, karena tari dero ini selain di tarikan oleh penari dero juga melibatkan para penonton dan masayarakat luas yang ingin ikut terlibat dalam tari dero tersebut sebagai wujud interaksi komunikasi dalam mengungkap ekspresi jiwa dalam medium tari.

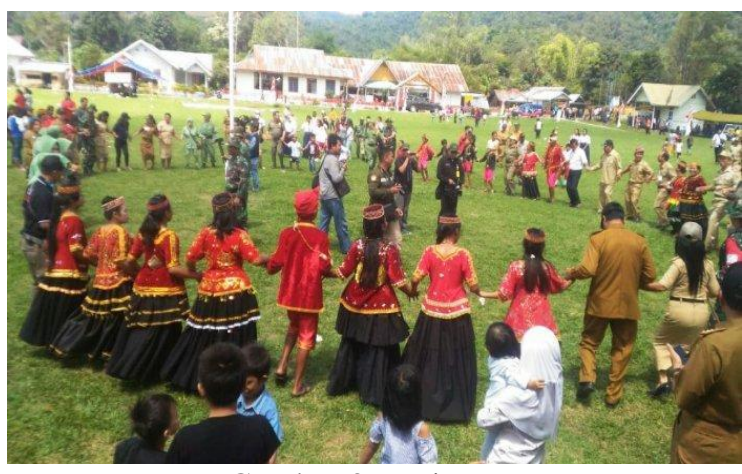

Gambar 3. Tari Dero

Menurut Balebu (2010) terdapat tujuh pilar utama baju adat wanita, yaitu:

a. Hiasan dada ornamen bentuk baki atau bingka. Adapun makna dari gambar baki atau bingka tersebut adalah kaum wanita sebagai pelayan bagi suami dan anakanaknya.

b. Hiasan dada ornamen bentuk daun melingkari dileher. Dimaknai bahwa kaum wanita Pamona dalam memberikan pelayanan disertai dengan hati yang tulus ikhlas. Pelayanan yang baik akan menjadikan nama mereka harum dan dikenang.

c. Hiasan dada bentuk bulatan kecil dalam baki. Artinya kaum wanita gemar menyimpan atau menabung. Hasil panen akan mereka simpan dilumbung sambil menunggu panen berikutnya.

d. Hiasan dada ornamen bentuk bintang. Dimaknai bahwa kaum wanita sangat religius sangat percaya kepada Tuhan, mereka selalu melaksanakan ucapan syukur atas hasil-hasil yang diperoleh. e. Hiasan pada ujung lengan baju ornamen bentuk suke/bambo. Ditangan seorang ibu, pendidikan dasar bagi anakanak Pamona diawali dari ayunan yang disebut Kobati.

f. Hiasan pada lingkaran pinggang ornamen bentuk bungkusan pinang. Bagi orang tua dimasa lalu yang gemar memakan pinang dan sirih akan menjadikan gigi mereka kuat dan tidak mudah rontok. Hiasan pada pinggang tersebut dimaknai bahwa janji setia yang diucapkan saat membuka pinangan dipegang kuat oleh kamu wanita Pamona dan mereka sangat setia dan terikat pada janji tersebut.

g. Simpul ikatan pada kain sarung bahagian pinggang. Rahasia rumah tangga tidak boleh diketahui orang lain selain suami dan isteri. Makna lain dari simpul tersebut, apabila terletak dibahagian kanan pinggang menandakan wanita telah bersuami, Terletak dibahagian pinggang sebelah kanan agak kebelakang menandakan wanita telah ditinggal suami. Dan apabila terletak disebelah kiri pertanda wanita masih muda atau belum pernah bersuami.

\section{Simpulan}

Kesimpulan dalam penelitian bahwa tarian dero memiliki makna umum sebagai bentuk rasa syukur dan rasa persatuan masyarakat tanpa memandang strata sosial namun makna dan nilai tersebut bergeser disebabkan adanya akulturasi budaya asing dengan menggunakan musik moderen yang dikolaborasi dengan budaya lain.

Pada keistimewaan makna gerak tari dero merupakan sebuah sajian gerak yang sederhana dan serempak di lakukan serta memiliki daya tarik tersendiri yang mampu untuk memberikan sugesti dan merasang keinginan semua orang untuk ikut terlibat dalam melakukan gerak tari dero. Jenis tarian ini adalah tarian tradisi kerakyatan yang mampu di ikuti dan di tarikan dengan seluruh masyarakat dalam ajang pesta adat dan tarian dero merupakan tarian pergaulan dari berbagai kalangan mengingat bahwa tari dero ini tujuanya adalah mempersatukan 
gerak. Tari dero di tampilkan pada upacara adat pesta perkawinan dan syukuran. Makna pola lantai bentuk lingkaran yang tidak putus dan terjaga dengan baik.

\section{Referensi}

Balebu, Yoseph. 2010. Tujuh Pilar Utama Mengenal Pakaian Adat Suku Pamona. Media Litbang Sulteng III No. (1).

Cangara, Hafied. 2006. Pengantar Ilmu Komunikasi. Jakarta : PT. Raja Grafindo Persada.

Casalba, Sidi. 1967. Asas kebudayaan Islam (Jakarta: Bulan Bintang)

Effendy, Onong Uchjana. 2009. Ilmu komunikasi: Teori dan Praktek.Bandung: PT. Remaja Rosdakarya.

Imrah. 2020. Learning Audio of Visualization Music Pontanu Dance to Develop Communication Ecosystem

Imrah. 2020. Cultivation, Education And Arts In The Meaning Of The Pontanu Dance Movement In The Disruptive Era,

Imrah. 2020. Inovasi Pembelajaran Seni Sekolah Dasar Berbasisi Kearifan Lokal Di Era Revolusi Industri 4.0

Kamarul. 2002. Makna Tarian Dero Di Kalangan Masyarakat Kecamatan Masamba Kabupaten Luwu Utara. Fakultas Dakwah dan Komunikasi Uin Alauddin Makassar

Koentjaraningrat. (2002). Pengantar Ilmu Antropologi. Jakarta: PT Rineka Cipta.

Kuntowijoyo, (2006). Budaya dan Masyarakat. Yogyakarta: Tiara Wacana Yogya.

Mame, A. Rahim. 1998. Adat dan Upacara Perkawinan Sulawesi Selatan
(Jakarta: Departemen Pendidikan dan Kebudayaan)

Mulyana, Deddy. 2004. Metodelogi Penelitian Kualitatif. Bandung : PT Remaja Rosdakarya.

Nardy, Hasyim. 2012. Persatuan Dua Budaya. Jakarta: Permana Ofsett.

Soekanto, Soerjono. (2012). Sosiologi Suatu Pengantar (Cetakan ke-44). Jakarta: PT Raja Grafindo Persada.

Syamsidi. M, Dr. GR. Lono Lastoro Siamtupang, MA tesis 2010,kajian budaya dan media mediasi perdamai dalam tari dero studi kasus kabupaten poso Sulawesi tengah

Rohidi, R.T. (2011). Metodologi Penelitian Seni. Semarang: Cipta Prima Nusantara Semarang.

Verdiansyah, D. 2004. Pengantar Ilmu Komunikasi. Jakarta : PT . Elex Media Komputindo.

https://www.tribunnewswiki.com/2021/07/ 28/tari-dero 